\title{
Comparing the Flow Properties of Bulk Solids by Tri-axial Shear, Unconfined Yield and Direct Shear Tests ${ }^{\dagger}$
}

\author{
Hiroshi Tsunakawa and Daizo Kunii \\ Dept. of Chemical Engineering \\ Yokohama National University*
}

Fumito Takagi and Minoru Sugita

Institute of Technology, Shimizu

Construction Co., Ltd.**

\author{
Tomio Tamura and Hideto Haze \\ Technical Research Institute, \\ Mitsui Construction Co., Ltd.***
}

\begin{abstract}
This paper discusses a comparison of the data of experiments obtained by using different shear tests methods in order to examine the confidence in the results of experiments on the flow properties of a bulk solid.

The angle of internal friction of dry granular materials, which has been measured by both a tri-axial shear tester and a fixed volume direct shear tester, increases with a decrease in the voidage of the specimen. Except for the extremely dense and loosely packed states, the experimental results of the angle of internal friction agree within about 3 degrees. There is however a difference of 3 to 5 degrees for a material in which the particle shape is deflective.

The flowability index of cohesive powders and wet materials is expressed by a ratio of the unconfined yield strength to the bulk density. The results of experiments on the flowability index are independent of the unconfined yield and direct shear tests.
\end{abstract}

\section{Introduction}

The flow properties of a bulk solid are important factors in designing various processes and operations relative to its use, as well as in evaluating its flowability. The flow properties are expressed in various ways, and the method and apparatus for their measurement are employed according to their relevance to the objective. From the viewpoint of designing

* 156, Tokiwadai, Hodogaya-ku, Yokohama, 240 TEL. 045 (335) 1451

** 3-4-7, Etchujima, Koto-ku, Tokyo, 135 TEL. 03 (643) 4311

*** 518-1, Komaki, Nagareyama, Chiba, 270-01 TEL. 0471 (55) 4611

$\dagger$ This report was originally printed in J. Soc. Powder Technology, Japan, 23, 678-684 (1986) in Japanese, before being translated into English with the permission of the editorial committee of the Soc. Powder Technology, Japan. processes, therefore, the data on the flow properties must be handled in light of objectivity and confidence. That is to say, where a flow property is measured by differing devices, whether the results agree or differ is an important question.

In this paper, a comparison is made between the data obtained by three different research institutions with respect to the flow properties of common or similar samples subject to triaxial shear tests, unconfined yield tests, and direct shear tests.

\section{Subjects and organization of studies}

The flow properties of a bulk solid are basically represented by a family of linear yield loci. However, it is not convenient to deal with the linear yield loci themselves as an object relevant to comparison of the data of the flow properties. 
Table 1 The system of the present study

\begin{tabular}{clll} 
Material & \multicolumn{1}{c}{ Flow property } & \multicolumn{1}{c}{ Testing method } & Research institute \\
\hline Dry granule & $\begin{array}{l}\text { Angle of internal } \\
\text { friction }\end{array}$ & Tri-axial shear test & Shimizu Construction Co., Ltd. \\
\hline $\begin{array}{l}\text { Powder and } \\
\text { wet granule }\end{array}$ & $\begin{array}{l}\text { Flowability } \\
\text { (a ratio of uncon- } \\
\text { fined yield strength } \\
\text { to bulk density) }\end{array}$ & Direct shear test & Yokohama National University \\
\cline { 3 - 4 } & & Direct shear test & Mitsui Construction Co., Ltd. and \\
\end{tabular}

Since the yield locus of a dry granular material generally assumes a straight line, it is convenient to deal with the angle of internal friction, which is the inclination formed by the line, as an object of comparison in considering the data of flow properties. However, with respect to a powder or wet granular material, the yield locus forms a curve. The flow properties cannot be represented singly by the angle of internal friction. The flow properties then characteristically include an unconfined yield strength into which the intergranular frictional force and cohesion are integrated. The flowability index, which is defined as a ratio of the unconfined yield strength to the bulk density, typically represents the flow properties of a cohesive bulk solid and must be dealt with by mutual comparison.

The test of the flow properties were undertaken by the three research institutions specified in Table 1. The data on the angle of internal friction of the dry granules was obtained by both tri-axial and direct shear tests, whereas the flowability indices of cohesive granules and powders were determined by unconfined yield and direct shear tests.

\section{The angle of internal friction of dry granules}

The reader is referred to the published related literature ${ }^{1)}$ or reference book $^{2)}$ for details about the tri-axial shear test, since this

Table 2 The conditions of the experiment of the triaxial shear tests and the direct shear tests

\begin{tabular}{lcc}
\hline \multicolumn{1}{c}{ Condition } & Tri-axial & Direct \\
\hline Specimen size $[\mathrm{mm}]$ & $50^{\mathrm{D}} \times 100^{\mathrm{H}}$ & $100^{\mathrm{D}} \times 10^{\mathrm{H}}$ \\
Stress range $[\mathrm{kPa}]$ & $100 \sim 1900$ & $0 \sim 100$ \\
Strain rate $[\% / \mathrm{min}]$ & $<0.5$ & 2.22
\end{tabular}

Table 3 The dry granules used in both the tri-axial and the direct shear tests

\begin{tabular}{lcl}
\multicolumn{1}{c}{ Material } & $\begin{array}{c}\text { Density } \\
{\left[\mathrm{t} / \mathrm{m}^{3}\right]}\end{array}$ & \multicolumn{1}{c}{$\begin{array}{c}\text { Particle size } \\
{[\mathrm{mm}]}\end{array}$} \\
Soma sand & 2.65 & $0.59 \sim 0.84$ \\
Yamakawa sand & 2.64 & $0.35 \sim 0.84$ \\
Toyoura sand & 2.64 & $0.105 \sim 0.297$ \\
& & $(0.21 \sim 0.25)^{*}$ \\
Silicon carbide & 3.20 & 0.21 (average) \\
Glass beads & 2.50 & $0.177 \sim 0.25$ \\
& & $(0.21 \sim 0.25)^{*}$
\end{tabular}

*) These samples were used in direct shear tests.

test is widely used mainly in the field of soil engineering, and the testing method and devices applied are standardized. On the other hand, the direct shear test is carried out by various types of devices and has not yet been standardized yet. The test is limited to the fixed volume direct shear tester used in the present experiments. The testing method and devices used are described in the literature ${ }^{3,4)}$.

Table 2 shows the main conditions of the experiment under which the tri-axial shear tests and the fixed volume direct shear tests were carried out. These conditions had no special features in common. Table 3 shows the five kinds of dry granules and their physical features that were subjected to the measurement of the angle of internal friction. Common samples were employed for the two testing methods with respect to Soma sand, Yamakawa sand, and silicon carbide, but the samples of Toyoura sand and glass beads used in the two tests were a little different in grain size.

Figure 1 shows the results obtained from the tri-axial shear tests on Toyoura sand. The specimens had a voidage at the initial packing $\epsilon_{0}$ of 0.463 . The minor principal stress (lateral pressure) $\sigma_{3}$ had four values $-0.098,0.196,0.294$, 


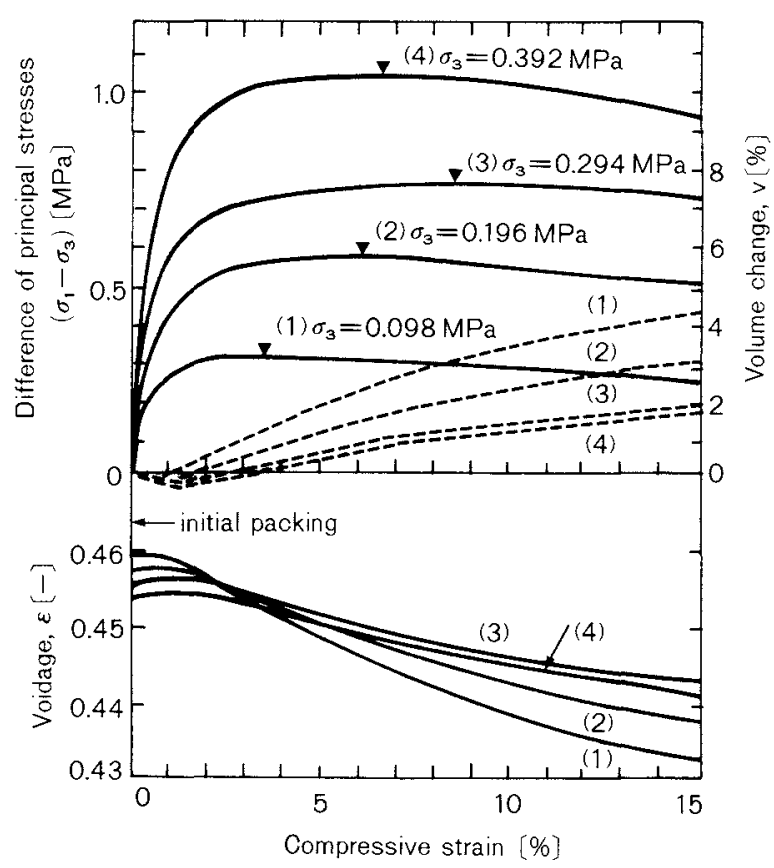

Fig. 1 The result of the tri-axial shear tests on Toyoura sand

and $0.392 \mathrm{MPa}$. These values were common to each of the tests. The difference in the principal stress, change in the volume, and change in the voidage were each plotted in relationship to the compressive strain. The voidage during failure was calculated by the equation.

$$
\epsilon=1-\left(1-\epsilon_{0}\right) /\left(1-v_{0}\right)(1-v)
$$

In this equation, $\epsilon_{0}$ represents the voidage at the initial packing, $v_{0}$ is the change in the volume after consolidation (when only $\sigma_{3}$ is applied), and $v$ is the change in the volume at the time of failure.

Upon determination of the maximum difference in principal stress as marked by $\mathbf{\nabla}$ in Fig. 1, Mohr's stress circles can be drawn as shown in Fig. 2. The straight line passing through the origin of the coordinates and tangent to the stress circles in the figure represents a yield locus. The angle of internal friction is represented as $35^{\circ}$ in Fig. 2. With respect to the voidage corresponding to the maximum difference in the principal stress, the values differ slightly from one another with the change in $\sigma_{3}$, as shown in Fig. 1. Thus, the voidages are shown as $0.452,0.449,0.448$, and 0.447 in the figure. It is a defect of the tri-axial shear testing method that the voidage cannot be made exactly the same for all tests. There-

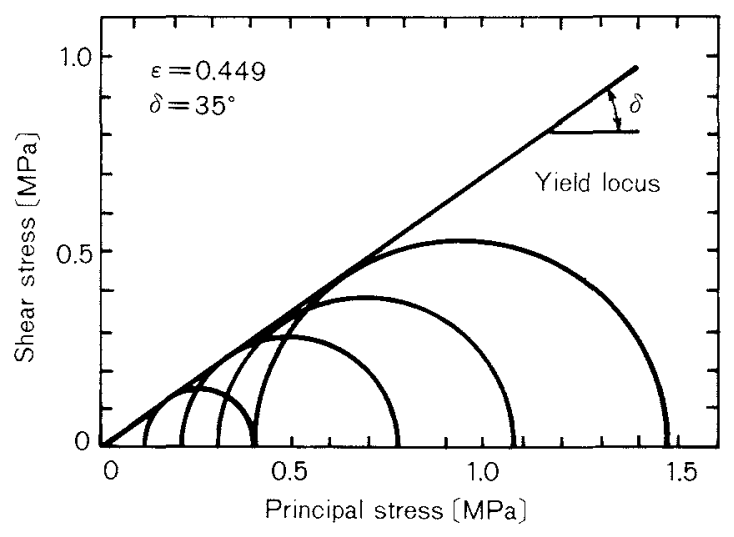

Fig. 2 The yield locus of Toyoura sand obtained from the tri-axial shear tests

Table 4 The results of the tri-axial shear tests

\begin{tabular}{|c|c|c|c|}
\hline \multirow[b]{2}{*}{ Material } & \multicolumn{2}{|c|}{ Voidage } & \multirow{2}{*}{$\begin{array}{l}\text { Angle of } \\
\text { internal } \\
\text { friction } \\
\delta \text { [deg.] }\end{array}$} \\
\hline & $\begin{array}{l}\text { at initial } \\
\text { packing } \\
\epsilon_{0}[-]\end{array}$ & $\begin{array}{c}\text { at failure } \\
\text { (average) } \\
\in[-]\end{array}$ & \\
\hline \multirow[t]{4}{*}{ Soma sand } & 0.463 & 0.449 & 32.0 \\
\hline & 0.433 & 0.417 & 36.0 \\
\hline & 0.376 & 0.354 & 39.5 \\
\hline & 0.354 & 0.329 & 40.25 \\
\hline \multirow[t]{4}{*}{ Yamakawa sand } & 0.434 & 0.420 & 33.75 \\
\hline & 0.417 & 0.400 & 34.5 \\
\hline & 0.365 & 0.348 & 38.5 \\
\hline & 0.357 & 0.335 & 40.0 \\
\hline \multirow[t]{4}{*}{ Toyoura sand } & 0.482 & 0.470 & 34.0 \\
\hline & 0.463 & 0.449 & 35.0 \\
\hline & 0.405 & 0.387 & 39.75 \\
\hline & 0.395 & 0.375 & 40.25 \\
\hline \multirow[t]{4}{*}{ Silicon carbide } & 0.519 & 0.509 & 31.5 \\
\hline & 0.496 & 0.483 & 32.0 \\
\hline & 0.427 & 0.408 & 35.5 \\
\hline & 0.415 & 0.393 & 36.25 \\
\hline Glass beads & 0.408 & 0.408 & $23.0^{*}$ \\
\hline
\end{tabular}

*) Quick test

fore, the mean value of the voidages is used as the voidage during failure in the processing data. Table 4 shows both the voidages and angles of internal friction obtained from the tri-axial shear tests.

Figure 3 shows a yield locus of Toyoura sand obtained by a fixed volume direct shear test. The yield locus can be determined by a single shear test where the vertical and horizontal components of the force generated at the step of shearing a specimen are simultaneously 


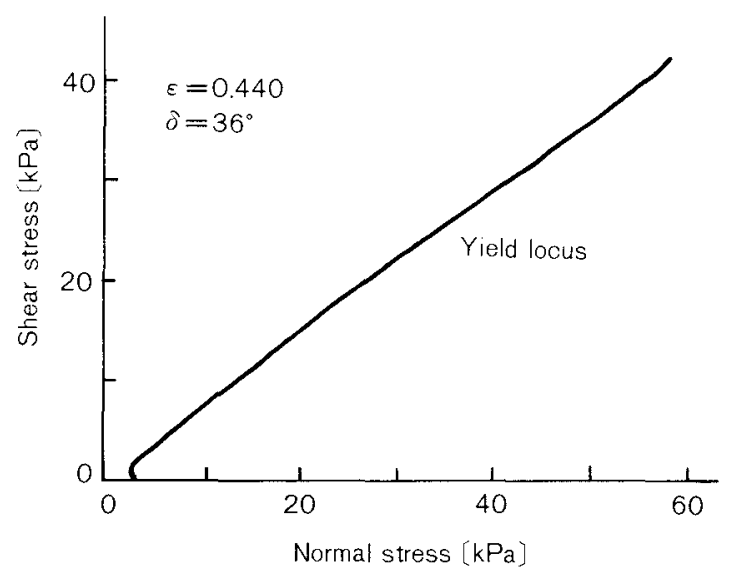

Fig. 3 The yield locus of Toyoura sand measured by the fixed volume direct shear tester

detected and output on an X-Y recorder. A yield locus can be regarded as forming a straight line passing through the origin. In Fig. 3, the angle of internal friction is shown as $36^{\circ}$. The voidage of the specimen at the initial packing $\epsilon_{0}$ is shown as 0.440 . In a fixed volume shear test, the voidage does not change during failure but remains the same as the value at the initial packing.

A comparison of the test results in Figs. 2 and 3 shows that even though there is a great difference in the ranges of the stresses applied for the measurement, the angles of internal friction show closeness in values due to the virtual uniformity of the voidage.

Figure 4 shows a comparison of the results obtained by tri-axial shear tests with those obtained by fixed volume direct shear tests on the relationship between the voidage and the angle of internal friction. In past tri-axial shear tests, the angle of internal friction was considred in relationship to the voidage at the initial packing $\epsilon_{0}$, but since the voidage during failure changes with compressive strain, as shown in Fig. 1, the voidage corresponding to the maximum difference in the principal stress must be considered.

The angle of internal friction increases with a decrease in the voidage independent of the testing methods. The results of two types of tests on Soma sand, Toyoura sand, and glass beads agree in the range from medium to loose in the packed state, but the values obtained by the direct shear tests are larger than those obtained by the other tests in the densely packed

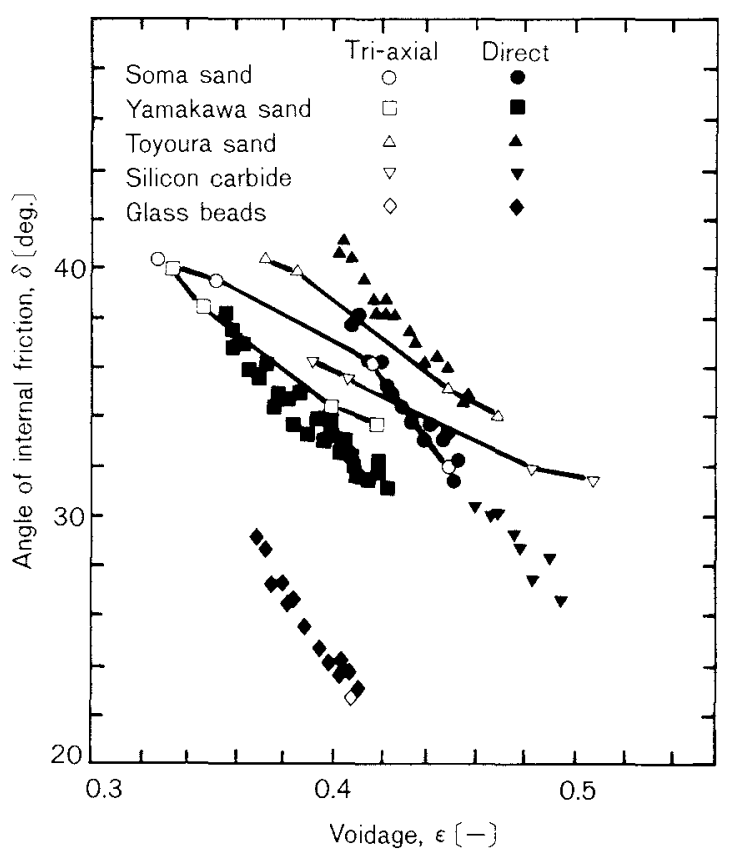

Fig. 4 A comparison of the angle of internal friction obtained from the tri-axial shear tests and the fixed volume direct shear tests

range. With respect to Yamakawa sand, the results agree on the whole, but there is a difference of up to $3^{\circ}$ in the loosely packed range.

With respect to silicon carbide, however, the values obtained clearly show differnces of $3^{\circ} \sim$ $5^{\circ}$ between the tri-axial shear tests and the fixed volume direct shear tests. The specimen of silicon carbide is a pulverized product, and the particles include those shaped almost like needles and flat particles. The distinct differences in the values obtained are considered to be due to a difference in how the shearing direction bears upon the disposition of the packed particles of the specimen between the two testing methods.

In Fig. 5, the results of shearing tests ${ }^{5)}$ carried out extensively by the Soil Engineering Society on sand (obtained at Onahama beach in Fukushima Prefecture, Japan) are shown as a relationship of the angle of internal friction to the initial void ratio. The sand had particle sizes of $0.1 \sim 0.5 \mathrm{~mm}$, and with the $50 \%$ diameter of $0.22 \mathrm{~mm}$, if somewhat resembled Toyoura sand. Figure 5 also shows the test results of Toyoura sand in the present study for comparison. Although the angles of internal friction differ slightly because of differences in the samples used, a close similarity is observed 


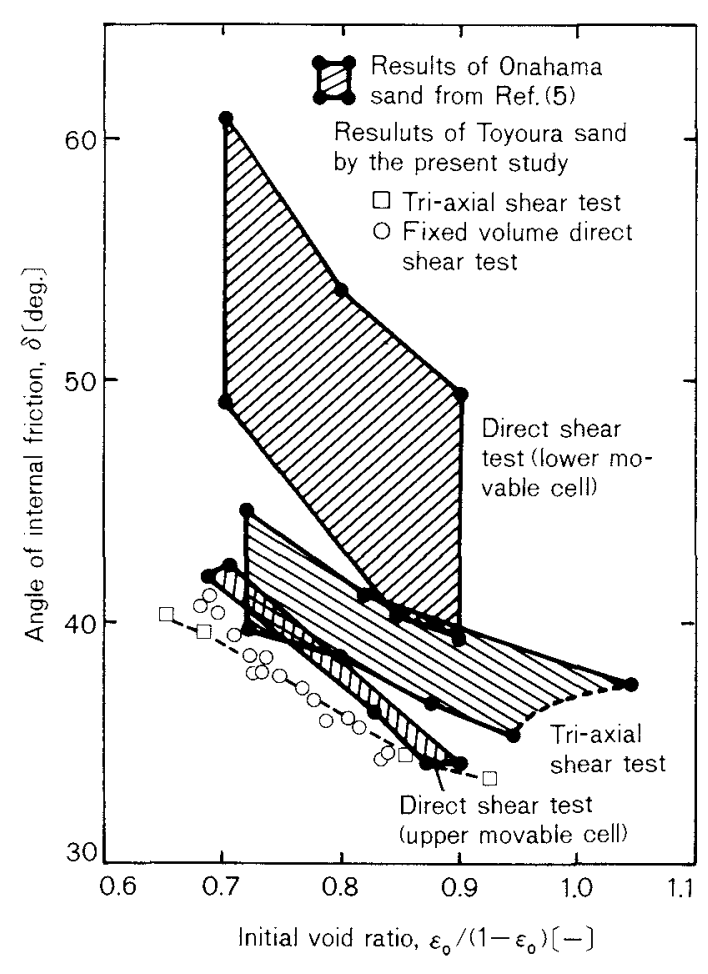

Fig. 5 A comparison of the angle of internal friction for Onahama sand and Toyoura sand measured by various types of shear testers

between the results of the Society's tests and those obtained in the present study for both the tri-axial and direct shear tests (the results of the Society's tests being based on uppermovable cells). Therefore, it is considered that there were no technical problems relating to the measurement in the present experiments.

It is said ${ }^{5)}$ that in the Society's extensive tests the results obtained by the use of lowermovable cell type devices for the direct shear tests showed larger deviations than all of the other comparable results, as well as a large degree of scatter, but the results were found lacking in confidence. The device used for the fixed volume direct shear tests in the present experiments was also of the lower-movable cell type, but the obtained results were similar to those obtained by the tri-axial shear tests and the upper-movable cell-based direct shear tests.

Whether the shearing cell is of the uppermovable type or of the lower-movable type does not seem to significantly affect the results of the direct shear tests. The problem is considered to lie in the structure of the testing device, or in the dimensions of the shearing cells, etc.

\section{The flowability of cohesive powder and granules}

The unconfined yield strength of a cohesive powder or granular material is an important property to consider ${ }^{6,7)}$ when a storage vessel for it is designed. This is because this property is closely related to blocking which occurs at or near the outlet of the vessel. The most direct method for measuring the unconfined yield strength is the unconfined yield test, which is standardized mainly in the field of soil engineering. It is also possible to obtain the unconfined yield strength from the data of a yield locus measured by the direct shear test. Next, a comparison is made of the results obtained from the two testing methods.

Table 5 shows the samples and dimensions of the specimens, etc. which were used in the experiments. Common samples were employed in the two testing methods with respect to calcium carbonate, limestone, and coal (A), whereas the samples of coal (B) used for the two respective testing methods were similar but differed in particle size and free moisture.

Figure 6 shows a record of the compressive

Table 5 The conditions of the experiment and materials used in the unconfined yield tests and the direct shear tests

\begin{tabular}{|c|c|c|c|c|c|c|c|c|}
\hline \multirow{3}{*}{$\begin{array}{l}\quad \text { Material } \\
\text { Condition } \\
\text { Testing method } \\
\text { Particle size }\end{array}$} & \multicolumn{2}{|c|}{ Calcium carbonate } & \multicolumn{2}{|c|}{ Lime stone } & \multicolumn{2}{|c|}{ Coal (A) } & \multicolumn{2}{|c|}{ Coal (B) } \\
\hline & U.Y.T. & D.S.T. & U.Y.T. & D.S.T. & U.Y.T. & D.S.T. & U.Y.T. & D.S.T. \\
\hline & $2.6 \mu \mathrm{m}$ & $2.6 \mu \mathrm{m}$ & $<3 \mathrm{~mm}$ & $<3 \mathrm{~mm}$ & $<3 \mathrm{~mm}$ & $<3 \mathrm{~mm}$ & $<10 \mathrm{~mm}$ & $<5.6 \mathrm{~mm}$ \\
\hline $\begin{array}{l}\text { Free moisture } \\
\qquad(\%)\end{array}$ & 0.20 & 0.18 & 4.1 & 4.07 & 12.6 & 12.6 & 8.3 & 7.8 \\
\hline $\begin{array}{r}\text { Specimen size } \\
{[\mathrm{mm}]}\end{array}$ & $18.8^{\mathrm{D}} \times 50^{\mathrm{H}}$ & $100^{\mathrm{D}} \times 10^{\mathrm{H}}$ & $50^{\mathrm{D}} \times 100^{\mathrm{H}}$ & $100^{\mathrm{D}} \times 10^{\mathrm{H}}$ & $50^{\mathrm{D}} \times 100^{\mathrm{H}}$ & $100^{D} \times 10^{H}$ & $100^{D} \times 200^{H}$ & $100^{\mathrm{D}} \times 10^{\mathrm{H}}$ \\
\hline
\end{tabular}

(Note: U.Y.T. shows the unconfined yield test and D.S.T. the direct shear test) 


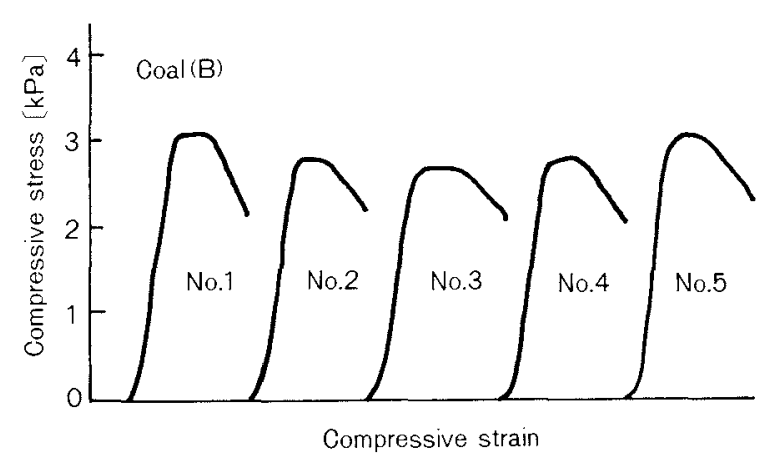

Fig. 6 Record of unconfined yield tests for coal (B)

stress applied to the coal (B) in an unconfined yield test. The peak value of the compressive stress was regarded as the unconfined yield strength $f$. The test was carried out five times, more or less, for the same bulk density, and then it was repeated likewise for a different bulk density. The specimens were composed of three to five vertical layers. The specimens had different sizes depending on the particle size, as shown in Table 5. The relationship between the consolidation stress and the bulk density was examined by a separate measurement. The details of the testing method are described in the literature ${ }^{7)}$.

Figure 7 shows a yield locus of the coal (B) obtained by a direct shear test. From the end point of the preliminary shearing step of a specimen, a continuous line representing the relationship between the normal stress and the shear stress was recorded to show the yield locus. The unconfined yield stress $f$ can be obtained as the diameter of the Mohr circle that

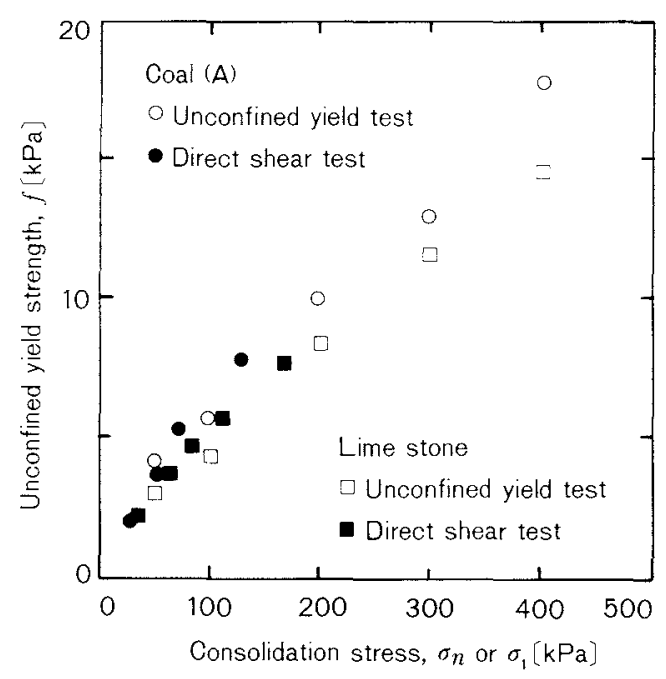

Fig. 8 A comparison of the unconfined yield strength of coal (A) and limestone obtained from the unconfined yield tests and the direct shear tests

passes through the origin of the coordinates and meets the yield locus at one point. The major consolidation stress $\sigma_{1}$ is shown by the Mohr circle which meets the yield locus at the end point. The bulk density is calculated from the packed volume and the mass of the specimen at the time when the preliminary shearing has ended. The details of the testing method etc. are described in the literature ${ }^{3)}$.

Figure 8 shows the unconfined yield strength of the coal (A) and limestone obtained by both the unconfined yield and direct shear tests. In this figure, the results of the unconfined yield tests are shown as the relationship of the unconfined yield strength $f$ to the consolidation stress $\sigma_{n}$, and the results of the direct shear

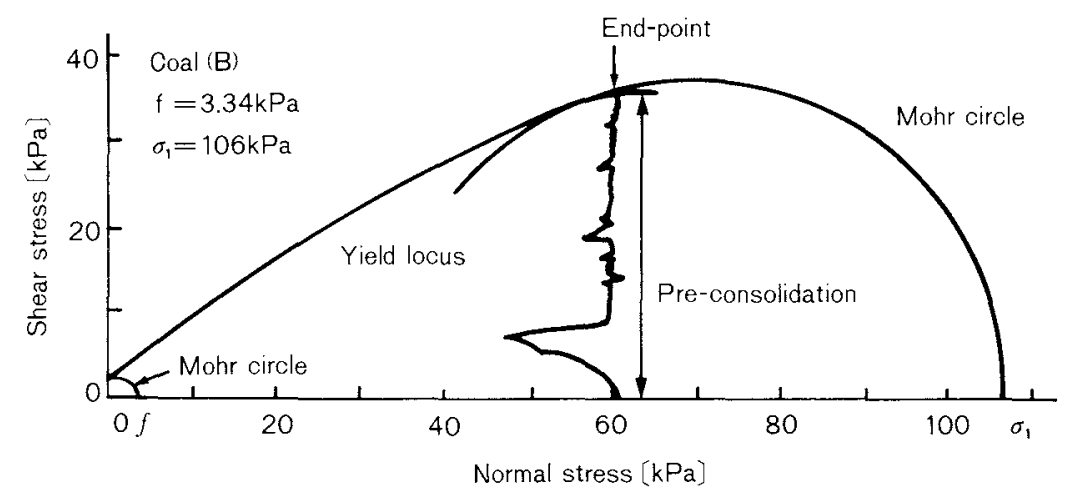

Fig. 7 The yield locus of coal (B) measured by the direct shear tester, and determination of the unconfined yield strength, $f$, and the major consolidation stress, $\sigma_{1}$ 


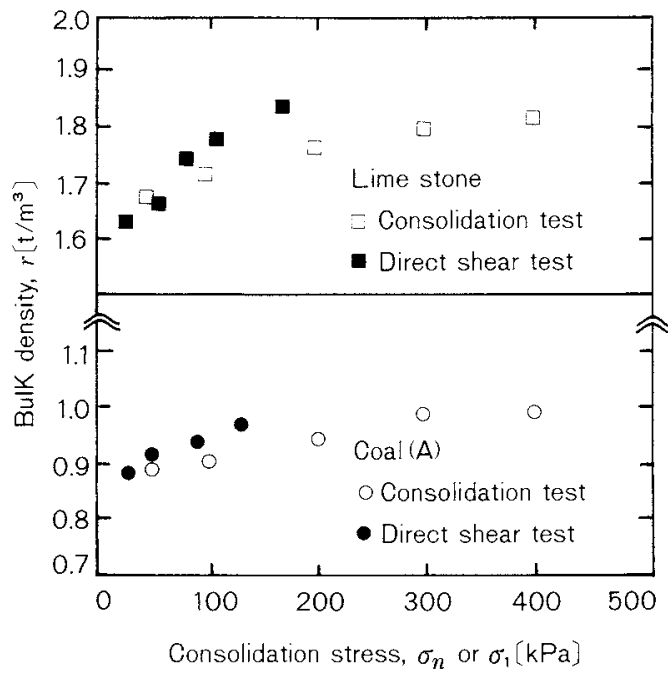

Fig. 9 A comparison of the bulk density of coal (A) and limestone obtained from the consolidation tests and the direct shear tests

tests are shown as the relationship of the unconfined yield strength $f$ to the major consolidation stress $\sigma_{1}$. The results of the two testing methods were relatively close, with the values obtained from the direct shear tests being slightly larger on the whole than those obtained from the other tests. This difference is considered to be due to shearing at the unconfined state of one method and a difference in the molding method for the specimens between the two testing methods. The latter reason lies in the fact that whereas the specimens used in the unconfined yield tests were molded by simple compression, those for the direct shear tests were molded through preliminary shearing.

Figure 9 shows the results of the bulk density $\gamma$ of coal (A) and limestone, obtained by the two testing methods. It is shown that the bulk density was larger, and the specimens were packed more densely for the direct shear test than for the unconfined yield test. As a result, the unconfined yield strength is considered to have shown a larger value during the direct shear test.

It was already reported ${ }^{3)}$ that the flowability of a cohesive powder or granular material can be evaluated by a flowability index expressed as $f / \gamma g$. This flowability index means the critical height up to which a molded body of powder maintains its shape and an increase in the value, which occurs with an increase in

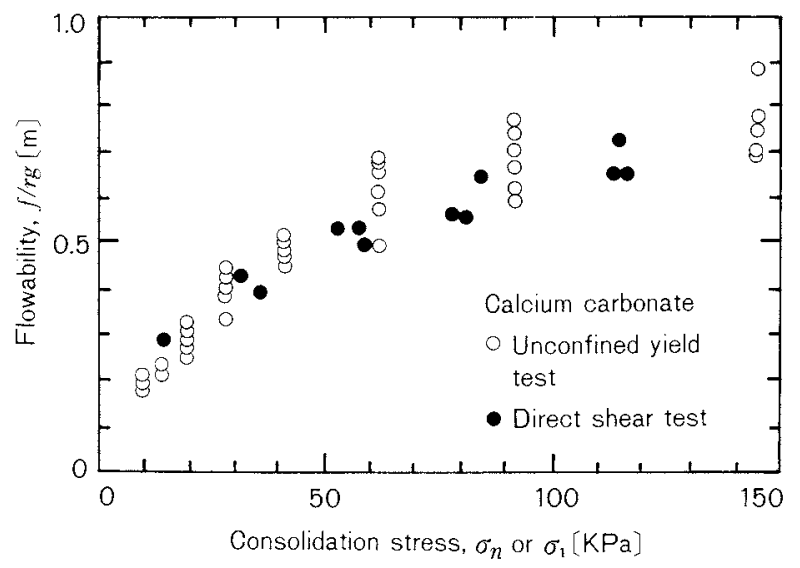

Fig. 10 A comparison of the flowability of calcium carbonate obtained from the unconfined yield tests and the direct shear tests

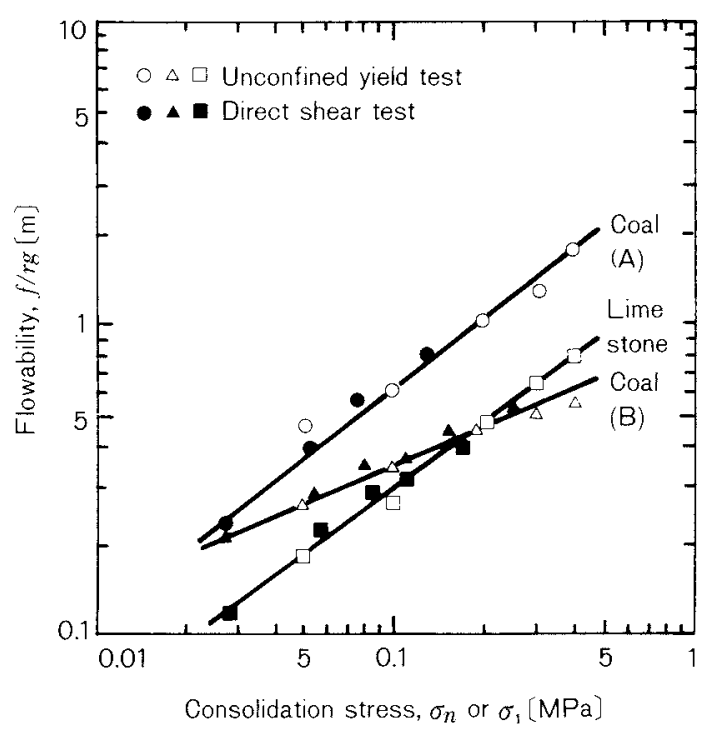

Fig. 11 A comparison of the flowability of wet coals and limestone obtained from both the unconfined yield tests and the direct shear tests

the cohesive force and frictional force between particles, signifies a degradation in the flowing property. The respective flowability indices obtained from both the unconfined yield and direct shear tests are shown in Figs. 10 and 11 for comparison. Although they show some scatter, the results of calcium carbonate, are almost in agreement for both testing methods. The unconfined yield tests of calcium carbonate were carried out by Yokohama National University, and those of the other three kinds of specimens were done by Mitsui Construction Co. 
The flowability indices obtained by the unconfined yield tests in Fig. 11 represent the averages of the results of tests carried out five times, as shown in Fig. 6. In Fig. 11, a fairly good agreement can be observed between the results obtained by the two testing methods with respect to the flowability of wet coals and limestone.

The relationship between the flowability index and the major compressive stress in the results of direct shear tests can be represented by Eq. (2), as already reported ${ }^{3,8)}$

$$
f / \gamma g=a \sigma_{1}{ }^{b}
$$

where $a$ and $b$ are coefficients proper to a powder, and $g$ is the acceleration of gravity.

As is clear from Fig. 11, Eq. (2) is also applicable to the results of unconfined yield tests if the compressive stress $\sigma_{n}$ is substituted for the major compressive stress $\sigma_{1}$. From the results obtained by the two testing methods, it is seen that Eq. (2) is valid for $\sigma_{1}$ or $\sigma_{n}$ in a range of approximately $20 \sim 500 \mathrm{kPa}$. If the results previously discussed ${ }^{3,8}$ are also taken into consideration, Eq. (2) is valid for a range of $1 \sim 500 \mathrm{kPa}$.

\section{Summary}

With a view to examining the results of differing testing methods in terms of their consistency, tri-axial shear tests were compared with fixed volume direct shear tests in the measurement of the angle of internal friction of dry granules. Unconfined yield tests were compared with direct shear tests in the measurement of the flowability indices of cohesive powder and granules. As a result, it was found that:

1) whereas the angle of internal friction of dry granules is dependent on the voidage, the values obtained by the two testing methods agree to within a difference of about $3^{\circ}$, except for the extremes of the voidage range where, even though the specimen grains have exceptional shapes, a difference of more than $3^{\circ}$ may arise depending on the testing method.

2) with respect to the flowability index of cohesive powder or granules, the values obtainable by the two testing methods agree relatively well. The flowability index can be expressed by Eq. (2) for the compressive stress or major compressive stress in the range of up to 500 $\mathrm{kPa}$.

\section{Nomenclature}

$$
\begin{aligned}
a & : \text { coefficient in Eq. (2) } \\
b & : \text { coefficient in Eq. (2) } \\
f & : \text { unconfined yield strength } \\
g & : \text { acceleration due to gravity } \\
v & : \text { volume change during failure } \\
v_{0} & : \text { initial volume change } \\
\gamma & : \text { bulk density } \\
\delta & : \text { angle of internal friction } \\
\epsilon & : \text { voidage during failure } \\
\epsilon_{0} & : \text { voidage at initial packing } \\
\sigma_{1} & : \text { major stress } \\
\sigma_{3} & : \text { minor stress } \\
\sigma_{n} & : \text { compressive stress }
\end{aligned}
$$

\section{References}

1) Takagi, F. and M. Sugita: J. Soc. Powder Technol, Japan, 16, 277 (1979).

2) Soc. Soil Mecha. and Fund. Eng.: "Doshitsu ShikenHo" (1979).

3) Tsunakawa, H.: J. Soc. Powder Technol., Japan, 19, 516 (1982).

4) Tsunakawa, H.: Powder Technol., 33, 249 (1982).

5) Yamada, K.: Tsuchi To Kiso, 13, 89 (1965).

6) Tsunakawa, H.: J. Soc. Powder Technol., Japan, 18, 405 (1981).

7) Tamura, T., H. Haze, M. Kato and T. Yamada: $J$. Soc. Powder Technol, Japan, 22, 511 (1985).

8) Tsunakawa, H.: Preprints of CHISA ' 84 Congress, Prauge (1984). 